\title{
Response of Moringa oleifera Callus and Plantlets to Mannitol-induced Drought Stress.
}

\author{
H.F. shaaban*and N. Maher \\ Botany Department, Faculty of Science, Ain Shams \\ University, Abbasia, Cairo, Egypt.
}

\begin{abstract}
$\mathrm{N}$ THIS work, we generated callus and micropropagated plants from Moringa oleifera to evaluate their response to drought stress induced by different concentrations of mannitol. Mannitol-induced drought stress caused a reduction shoot and root length as well as fresh and dry weights of shoots and roots in micropropagated plants. In addition, chlorophyll (a and b) and carotenoids contents were reduced. Such a reduction was concomitant with increases in soluble sugars, proline, malondialdehyde (MDA), ascorbic acid (ASA), reduced glutathione (GSH) and total phenols content in both callus and micropropagated plants. Moreover, the activities of catalase (CAT), superoxide dismutase (SOD), polyphenol oxidase (PPO) increased in micropropagated plants parallel with decreases in peroxidase (POX), ascorbate peroxidase (APX) and ascorbate oxidase (ASO) activities. On the other hand, the activities of CAT, SOD, POX, PPO, ASO increased in callus coupled with a decrease in APX. Our data indicated that micropropagated plants are more sensitive to drought stress, compared to callus as evidenced by greater accumulation of MDA while callus accumulated more soluble sugar, proline, GSH and total phenols than micropropagated plants.
\end{abstract}

Keywords: Moringa oleifera, Callus, Micropropagation, Drought stress, Abiotic stress, Mannitol.

\begin{abstract}
Abbreviations : MDA: Malondialdehyde, ASA: Ascorbic acid, GSH: Reduced glutathione, CAT: Catalase, SOD: Superoxide dismutase, PPO: Polyphenol oxidase, POX: Peroxidase, APX: Ascorbate peroxidase, ASO: Ascorbate oxidase, MS: Murashige and Skoog, SIM: Shoot induction medium, SEM: Shoot elongation Medium, 2, 4-D: 2,4-dichlorophenoxyacetic acid, IAA: indole-3acetic acid, 2-ip: 2-isopentyladenosine, NAA: Naphthaline acetic acid,

IBA: Indole-3-butyric acid, BA: benzyladenine, ROS: Reactive oxygen species.
\end{abstract}

Abiotic stress limits crop productivity, and plays a major role in determining the distribution of plant species across different types of environments. Recently, the effects of abiotic stress on plants in both natural and agricultural settings 
receive more attention because of the potential impacts of climate change on rainfall patterns, temperature extremes, salinization, and the overall need to maintain or increase agricultural productivity (Boyer, 1982 and Araus et al., 2002). Plant biotechnology can help plant breeders by creating and manipulating genetic variability. The contribution of plant biotechnology in plant breeding includes improving both crop quantity and quality (Jauhar 2005).

Water deficit is one of the most important environmental disturbances, which influence the distribution of many species from year to year leading to a tremendous loss all over the world. The tissue culture technique is one of the novel approaches to overcome this problem. The main idea in this respect is that cultivated cells are used as selected units rather than whole plants (Moffat, 1996; Ehsanpour and Amini, 2003). Osmoregulators such as mannitol and sugar alcohols are used to control the osmotic potential in the culture media or nutrient solutions in order to induce water deficit conditions (Zang and Komatsu, 2007).

Moringa oleifera is the best known species of the Moringaceae family (Morton,1991). Moringaceae is a family of plants belonging to order Brassicales; among Angiosperms. It is represented by fourteen species and a single genus (Moringa). It is a shrub or small tree which is fast growing, reaching 12 meters in height (Keer and Silva, 1999). It is cultivated for its food, medicinal and culinary value, especially its leaves (Fuglie, 1999). There are tremendous potential opportunities with $M$. oleifera for sustainable agriculture and the development of cash crops in semiarid regions. The few reports on the tissue culture of $M$. oleifera described clonal propagation through the use of nodal explants taken from non-aseptic sources, either from young seedlings or mature plants (Stephenson and Fahey, 2004; Islam et al., 2005 and Marfori, 2010). The preservation of Moringa spp. is thus of great concern for biodiversity, ethnobotanical, dietary and pharmacological perspectives.

The aim of the present study is to show the response of $M$. olifera callus and micropropagated plantlets to mannitol-induced drought conditions in an attempt to understand the complex mechanisms of drought stress in plants.

\section{Materials and Methods}

\section{Plant materials, medium composition and cultural conditions}

Healthy uniform seeds of $M$. oleifera were obtained from the botanic garden, Faculty of Science, Ain Shams University, Cairo, Egypt. Seed coats were removed aseptically and seeds were surface sterilized by immersion in $20 \%$ sodium hypochlorite $(v / v)$ for $15 \mathrm{~min}$, followed by rinsing three times in sterile distilled water. Seeds were planted aseptically in MS basal medium (Murashige and Skoog, 1962) containing $30 \mathrm{~g} / \mathrm{l}$ sucrose solidified with $8 \mathrm{~g} / \mathrm{l}$ agar. The $\mathrm{pH}$ was adjusted to 5.8 , after which the medium was dispensed at $40 \mathrm{ml}$ each in 
culture bottles and sterilized by autoclaving at $121{ }^{\circ} \mathrm{C}$ for $20 \mathrm{~min}$. Seed cultures were maintained in the dark at $27 \pm 1{ }^{\circ} \mathrm{C}$ for 15 days. Upon germination, seedlings were transferred to continuous light at 2000-Lux intensity produced from cool white fluorescent lamps.

\section{Callus induction and callus growth}

The seedlings consisting of 3-4 nodes were used in this experiment. Leaf explants were prepared and transferred to MS callus induction medium consisting of MS mineral salts and vitamins supplemented with BAP $(4-18 \mu \mathrm{M})$ and -2,4$\mathrm{D}(0.5-1.5 \mu \mathrm{M})$ containing $3 \%$ sucrose Mylene et al. (2011). The $\mathrm{pH}$ was adjusted to $5.8 \pm 0.02$ with $1 \mathrm{~N} \mathrm{KOH}$ or $1 \mathrm{~N} \mathrm{HCl}$ before autoclaving at $121^{\circ} \mathrm{C}$ for 20 min. Cultures were maintained in a growth chamber set at $25 \pm 2{ }^{0} \mathrm{C}, 70 \%$ relative humidity and a 16/8 h (light/dark) photoperiod with light supplied by cool-white fluorescent lamps at an intensity of 2 000-Lux. Five explants were cultured per jar. After eight weeks incubation (subculturing occurred every 2 weeks), the calli were excised and sub-cultured on MS medium and under the same growth conditions with four level concentrations of mannitol (0, 100. 200 and $300 \mathrm{mM}$ ). The media were replaced twice during the four week incubation period of the experiment.

\section{Micropropagation studies}

Micropropagation studies were carried out with nodal explants. The nodal explants were prepared and transferred to a shoot induction medium (SIM) consisting of MS salts and benzylamino purine (2pi) at $0-20 \mathrm{mg} / \mathrm{l}$ and naphthaline acetic acid (NAA) at $0-3 \mathrm{mg} / \mathrm{l}$ to determine their effect on multiple axillary shoot formation. The percentage of response in terms of number of shoots per explants and shoot length were recorded after15 days from transferring to SIM medium. The obtained micropropagated shoots were then repeatedly subcultured on MS basal medium supplemented with $4 . \mathrm{mg} / \mathrm{l} \mathrm{BA}$ as shoot elongation Medium (SEM) Saini et al. (2013). The cultures were maintained in a sterile growth room with $16 \mathrm{~h}$ photoperiod at $25 \pm 2{ }^{0} \mathrm{C}$ with light intensity of 2000 lux and $65 \%$ relative humidity. Rooting was initiated on MS medium supplemented with $3 \mathrm{mg} / 1$ indole-3-butyric acid (IBA) under the same conditions.

\section{Effect of mannitol on micropropagated plants}

The plantlets were transferred to a hormone free medium supplemented with different concentrations of mannitol (0, 100, 200 and $300.0 \mathrm{mM})$. The jars were incubated in a growth chamber under fluorescent light and at an ambient temperature of $25 \pm 2{ }^{\circ} \mathrm{C}$ for four weeks. The medium was replaced every 15 days. The plants were then harvested and the morphological criteria as well as the biochemical and the physiological parameters were assayed. 
Extraction and estimation of photosynthetic pigments

The concentrations of photosynthetic pigments (chlorophyll a, chlorophyll $b$ and carotenoids) were estimated following the method of Metzner et al. (1965).

\section{Extraction and estimation of carbohydrates}

The total soluble carbohydrates were extracted as described by Homme et al. (1992). Soluble sugar was determined spectrophotometrically according to the method of Blakeney and Mutton (1980).

Extraction and estimation of proline

The free proline content was extracted and determine according to the method of Bates et al. (1973).

\section{Estimation of Lipid peroxidation}

Lipid peroxidation product was extracted in $0.5 \%(\mathrm{w} / \mathrm{v})$ thiobarbituric acid and $20 \%(\mathrm{w} / \mathrm{v})$ trichloroacetic acid at $95{ }^{\circ} \mathrm{C}$ for $30 \mathrm{~min}$. then measured using the spectrophotometric method described by Heath and Packer (1968).

\section{Estimation of Reduced glutathione}

Reduced glutathione (GSH) was extracted in a solution of $1.0 \mathrm{mM}$ of EDTA with $50 \mu \mathrm{IClO}_{4}$, then measured spectrophotometry (Hissin and Hilf, 1976).

\section{Estimation of Ascorbic acid}

Ascorbic acid was extracted with $6 \%$ trichloroacetic acid then measured spectrophotometrically (Mukherjee and Choudhuri, 1983).

\section{Estimation of Total phenols content}

Total phenols were extracted by methanol and determined by FolinCiocalteu reagent assay following the method described by Malik and Singh (1980).

\section{Estimation of Antioxidant enzymes}

The antioxidant enzymes were extracted in phosphate buffer, $\mathrm{pH} 6.8$ (Mukherjee and Choudhuri, 1983). The crude extract was used for enzyme assay. Superoxide dismutase activity (SOD EC 1.15.1.1) was determined by measuring the inhibition of the auto-oxidation of pyrogallol using a method described by Marklund and Marklund (1974). Catalase activity (CAT EC 1.11.1.6) was assayed according to the method by Chen et al. (2000). Peroxidase (POX EC 1.11.1.7) and polyphenol oxidase (PPO EC 1.10.3.1) activities were assayed according to the method of Kar and Mishra (1976). Ascorbate oxidase activity (ASO EC 1.10.3.3) was measured according to the method of Diallinas et al. (1997). Ascorbate peroxidase (APX EC 1.11.1.1) activity was measured according to the method described by Koricheva et al. (1997).

Egypt. J. Bot., 56, No. 3 (2016) 


\section{Statistical analysis}

Data were analyzed statistically by ANOVA (analysis of variance) with subsequent comparison of means by the least significant difference (LSD).

\section{Results}

Induction and growth of callus under the effect of mannitol

Calli were initiated on the top surfaces of the explant after three weeks of culture incubation on MS medium supplemented with 2,4-D $(0.75 \mu \mathrm{M})$ and BAP $(12 \mu \mathrm{M})$ (Figure1, and Table 1). Data included in Table 1 indicates that calli emerged from leaf explants of $M$. oleifera showed the highest percentage of formation $(96 \%)$. These calli were also found to be characterized with a white color and homogenous texture (Fig. 1). The results of the present investigation showed a reduction in the callus fresh weight associated with increasing compactness and color browning was noticed after 4 weeks treatment with mannitol (Fig.1 and Table 3). The above mentioned symptoms were progressively increased as mannitol concentration increased in MS media as clearly shown in Figure 1.

TABLE 1. Percentage of calli (8 weeks) induced on Murashige \& Skoog (MS) medium supplemented with 2,4-dichlorophenoxy acetic acid (2,4-D) and Benzyl aminopurine (BAP). Results are shown as means of 10 replicates $\pm \mathrm{SE}$.

\begin{tabular}{|c|l|l|l|l|l|}
\hline $\begin{array}{c}\mathbf{2 , 4 - D} \\
(\boldsymbol{\mu M}) \\
(\boldsymbol{\mu M})\end{array}$ & \multicolumn{1}{|c|}{$\mathbf{0 . 5}$} & \multicolumn{1}{|c|}{$\mathbf{0 . 7 5}$} & \multicolumn{1}{|c|}{$\mathbf{1 . 0}$} & \multicolumn{1}{c|}{$\mathbf{1 . 2 5}$} & \multicolumn{1}{c|}{$\mathbf{1 . 5}$} \\
\hline 4 & $41.0 \pm 1.014^{\mathrm{a}}$ & $38.0 \pm 0.568^{\mathrm{a}}$ & $36.6 \pm 0.458^{\mathrm{a}}$ & $34.5 \pm 1.212^{\mathrm{a}}$ & $31.4 \pm 0.458^{\mathrm{a}}$ \\
\hline 6 & $56.4 \pm 0.651^{\mathrm{b}}$ & $55.1 \pm 0.624^{\mathrm{b}}$ & $52.3 \pm 0.458^{\mathrm{b}}$ & $47.0 \pm 1.101^{\mathrm{b}}$ & $44.5 \pm 0.655^{\mathrm{b}}$ \\
\hline 8 & $71.0 \pm 0.665^{\mathrm{c}}$ & $68.3 \pm 0.850^{\mathrm{c}}$ & $66.0 \pm 1.014^{\mathrm{c}}$ & $62.1 \pm 0.585^{\mathrm{c}}$ & $59.0 \pm 0.200^{\mathrm{c}}$ \\
\hline 10 & $84.4 \pm 0.458^{\mathrm{d}}$ & $82.2 \pm 1.059^{\mathrm{d}}$ & $79.0 \pm 1.637^{\mathrm{d}}$ & $76.5 \pm 0.763^{\mathrm{d}}$ & $73.0 \pm 0.721^{\mathrm{d}}$ \\
\hline 12 & $94.1 \pm 0.451^{\mathrm{e}}$ & $96.0 \pm 0.987^{\mathrm{f}}$ & $93.4 \pm 0.472^{\mathrm{f}}$ & $91.2 \pm 0.233^{\mathrm{fg}}$ & $89.5 \pm 0.360^{\mathrm{f}}$ \\
\hline 14 & $93.2 \pm 0.655^{\mathrm{e}}$ & $96.0 \pm 0.700^{\mathrm{f}}$ & $92.6 \pm 0.264^{\mathrm{f}}$ & $88.8 \pm 0.435^{\mathrm{ef}}$ & $86.3 \pm 0.404^{\mathrm{e}}$ \\
\hline 16 & $97.0 \pm 0.251^{\mathrm{f}}$ & $95.0 \pm 0.361^{\mathrm{f}}$ & $94.2 \pm 0.964^{\mathrm{f}}$ & $92.1 \pm 0.900^{\mathrm{g}}$ & $90.7 \pm 0.907^{\mathrm{f}}$ \\
\hline 18 & $94.2 \pm 0.416^{\mathrm{e}}$ & $92.4 \pm 0.611^{\mathrm{e}}$ & $89.5 \pm 1.040^{\mathrm{e}}$ & $87.4 \pm 0.233^{\mathrm{e}}$ & $86.1 \pm 0.556^{\mathrm{e}}$ \\
\hline LSD at $0.05 \mathrm{P}^{2}$ & 0.8626 & 1.0639 & 1.2685 & 1.0861 & 0.8103 \\
\hline
\end{tabular}




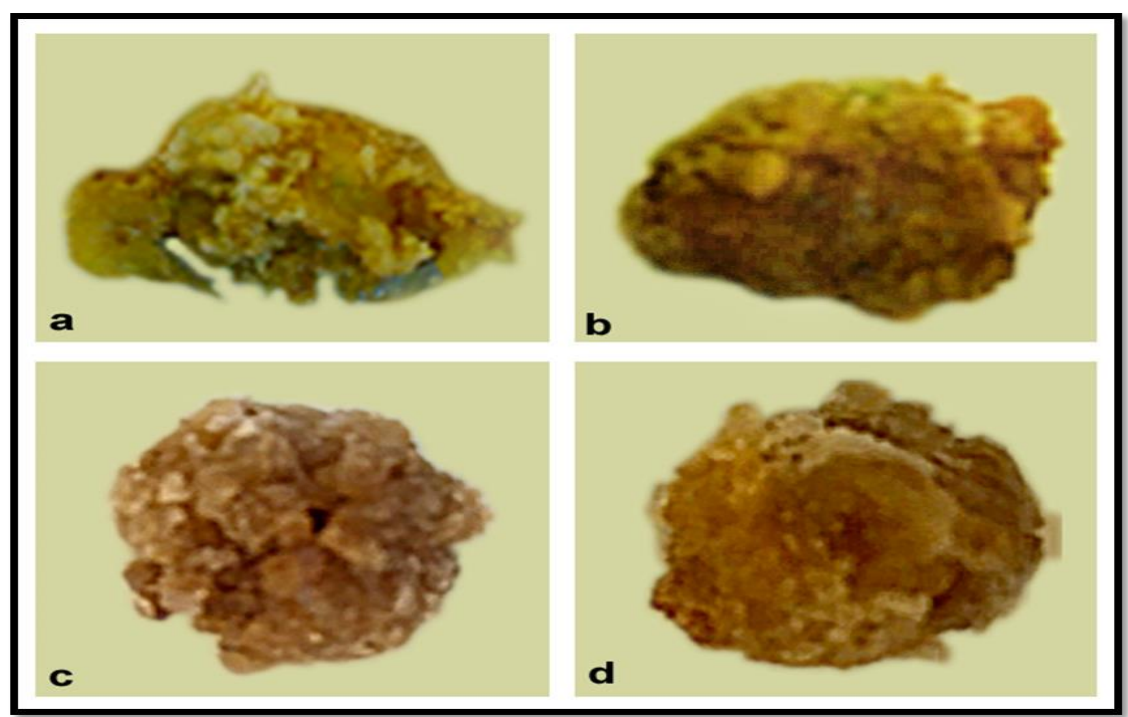

Fig. 1. Callus morphology (12 weeks) incubated with different concentrations of mannitol.

Control (a) with no mannitol, b: 100, c: 200, d: 300 mM mannitol for 4 weeks.

\section{Micropropagation}

Shoot micropropagation was obtained from the nodal segments developed from germinated plants under aseptic conditions. Table 2 shows that the cultured shoots length reached about $8 \mathrm{~cm}$ with 4-5 internodes and leaves accompanied by a well appearance after five weeks growth in shoot induction medium (SIM) containing 18 $\mathrm{mg} / \mathrm{l} 2$ ip and $2 \mathrm{mg} / \mathrm{l} \mathrm{NAA}$ and 2 weeks shoot elongation medium (SEM) containing $4 \mathrm{mg} / \mathrm{l} \mathrm{BAP}$. The well-developed and healthy shoots were transferred to root induction medium (RIM) containing $3 \mathrm{mg} / \mathrm{l} \mathrm{IBA}$. Roots with 3-4 laterals were induced by the end of the first week. All the micropropagated plantlets were morphologically similar and also resembled their respective mother plants.

\section{Effect of different concentrations of mannitol on callus and micropropagated plantlets growth}

Growth rate of both callus cells and the micropropagated platelets decreased through the 4 weeks of subculturing on MS medium containing different levels of mannitol. Results included in (Table 4, Fig. 2) show a significant decrease in the growth rate parameters as mannitol concentration increased in the culture media. The effect of mannitol on callus cells was more pronounced at $300 \mathrm{mM}$ mannitol followed by 200 and $100 \mathrm{mM}$, respectively. Although there was a difference in growth between the control and the mannitol-treated cells, there was no significant differences between different levels of treatments. However, the values of fresh and dry weights were progressively decreased with increasing mannitol concentration (Table 4). In general, the results obtained showed that, addition of mannitol caused a reduction in shoot and root elongation rates as well as the fresh and dry weights.

Egypt. J. Bot., 56, No. 3 (2016) 
RESPONSE OF MORINGA OLEIFERA CALLUS AND PLANTLETS .. 653

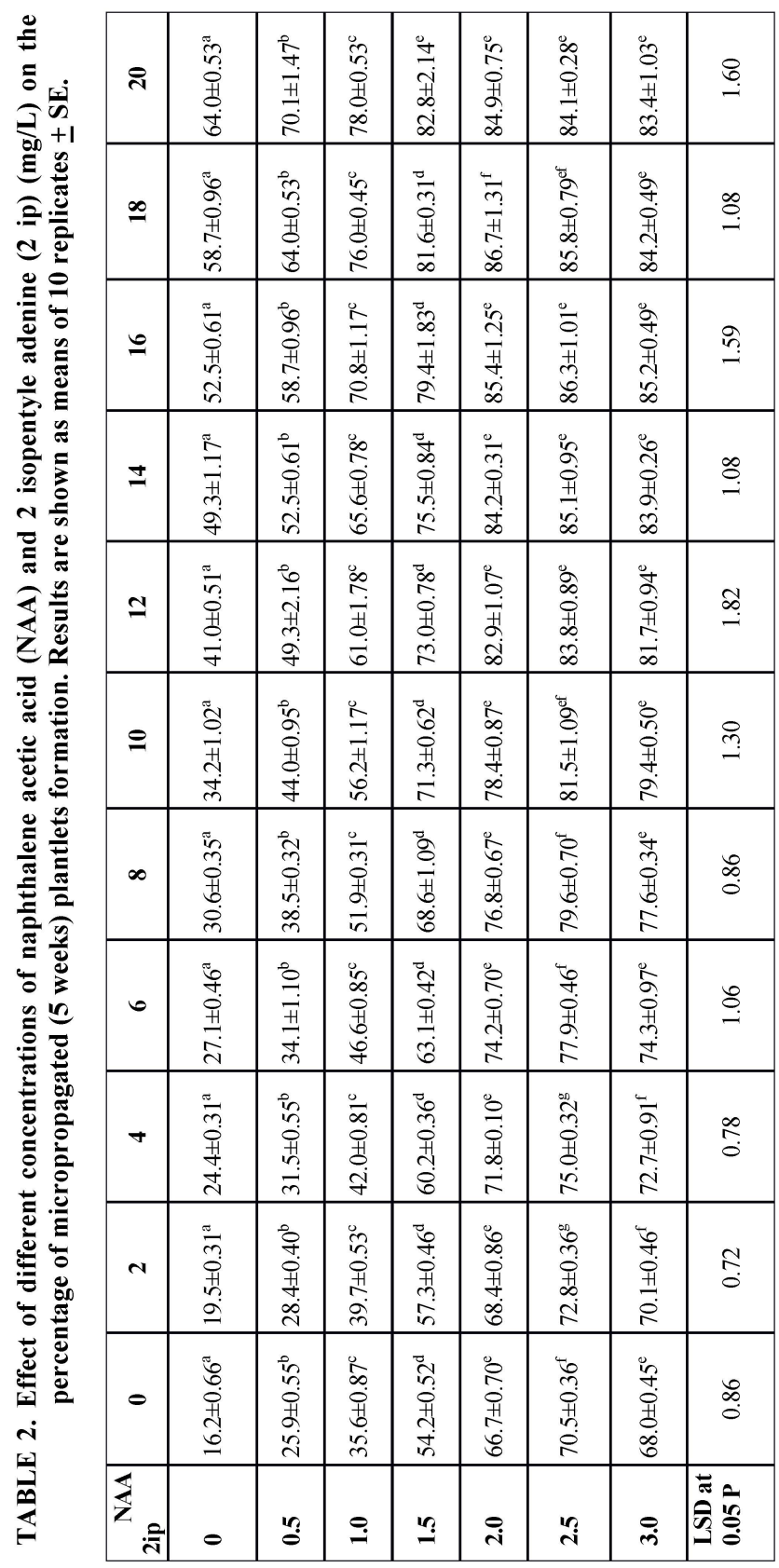

Egypt. J. Bot., 56, №. 3 (2016) 
TABLE 3. Callus fresh weight (g) incubated on Murashige \&Skoog (MS) medium supplemented with 2,4-dichlorophenoxy acetic acid (2,4-D) and Benzyl aminopurine(BAP) as growth regulators. Results are shown as means of 10 replicates $\pm \mathrm{SE}$.

\begin{tabular}{|l|c|c|c|c|c|}
\hline $\begin{array}{r}2,4-D \\
(\mu \mathrm{M})\end{array}$ & $\mathbf{0 . 5}$ & $\mathbf{0 . 7 5}$ & $\mathbf{1}$ & $\mathbf{1 . 2 5}$ & $\mathbf{1 . 5}$ \\
\hline 4 & & & & & \\
\hline 6 & $0.34 \pm 0.008^{\mathrm{a}}$ & $0.32 \pm 0.004^{\mathrm{a}}$ & $0.31 \pm 0.003^{\mathrm{a}}$ & $0.29 \pm 0.010^{\mathrm{a}}$ & $0.26 \pm 0.003^{\mathrm{a}}$ \\
\hline 8 & $0.47 \pm 0.005^{\mathrm{b}}$ & $0.46 \pm 0.005^{\mathrm{b}}$ & $0.44 \pm 0.003^{\mathrm{b}}$ & $0.39 \pm 0.009^{\mathrm{b}}$ & $0.37 \pm 0.005^{\mathrm{b}}$ \\
\hline 10 & $0.59 \pm 0.005^{\mathrm{c}}$ & $0.57 \pm 0.006^{\mathrm{c}}$ & $0.55 \pm 0.008^{\mathrm{c}}$ & $0.52 \pm 0.004^{\mathrm{c}}$ & $0.49 \pm 0.011^{\mathrm{c}}$ \\
\hline 12 & $0.70 \pm 0.003^{\mathrm{d}}$ & $0.69 \pm 0.008^{\mathrm{d}}$ & $0.66 \pm 0.013^{\mathrm{d}}$ & $0.64 \pm 0.006^{\mathrm{d}}$ & $0.61 \pm 0.006^{\mathrm{d}}$ \\
\hline 14 & $0.78 \pm 0.003^{\mathrm{e}}$ & $0.80 \pm 0.007^{\mathrm{f}}$ & $0.78 \pm 0.003^{\mathrm{f}}$ & $0.76 \pm 0.004^{\mathrm{f}}$ & $0.75 \pm 0.003^{\mathrm{f}}$ \\
\hline 16 & $0.78 \pm 0.005^{\mathrm{e}}$ & $0.80 \pm 0.005^{\mathrm{f}}$ & $0.77 \pm 0.002^{\mathrm{f}}$ & $0.74 \pm 0.003^{\mathrm{e}}$ & $0.72 \pm 0.003^{\mathrm{e}}$ \\
\hline 18 & $0.81 \pm 0.002^{\mathrm{f}}$ & $0.79 \pm 0.003^{\mathrm{f}}$ & $0.79 \pm 0.008^{\mathrm{f}}$ & $0.77 \pm 0.006^{\mathrm{f}}$ & $0.76 \pm 0.007^{\mathrm{f}}$ \\
\hline LSD at $0.05 \mathrm{P}$ & $0.79 \pm 0.003^{\mathrm{e}}$ & $0.77 \pm 0.005^{\mathrm{e}}$ & $0.75 \pm 0.003^{\mathrm{e}}$ & $0.73 \pm 0.002^{\mathrm{e}}$ & $0.72 \pm 0.004^{\mathrm{e}}$ \\
\hline
\end{tabular}

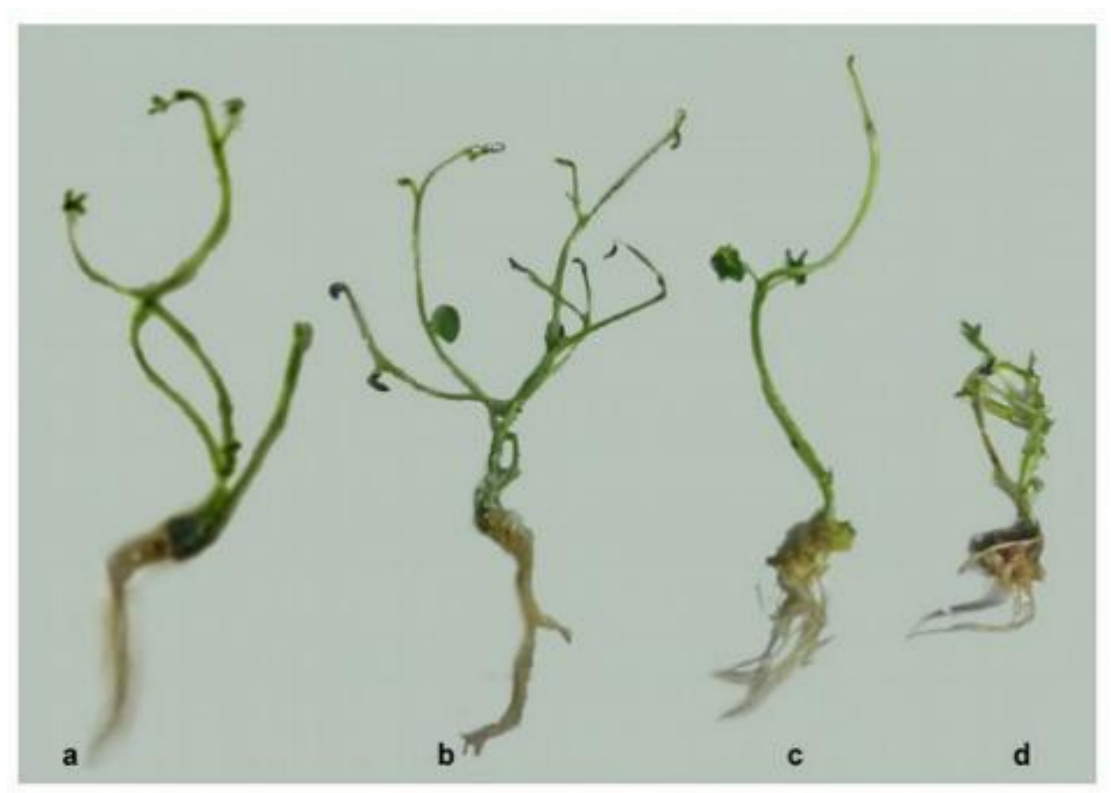

Fig.2. Showing micropropagated plants (4 months) incubated with different concentrations of mannitol a, $0, b, 100 \mathrm{c}, 200, \mathrm{~d} 300 \mathrm{mM}$ mannitol. 
TABLE 4. Effect of drought-induced by mannitol on some growth parameters of Moringa olifera micropropagated plantlets. Results are shown as means of three replicates $\pm \mathrm{SE}$.

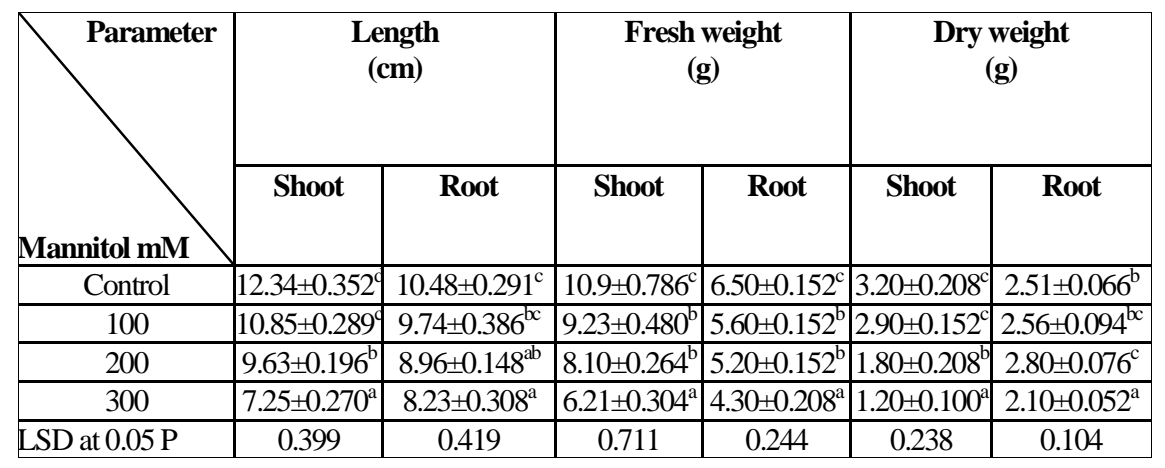

Effect of mannitol-induced drought on pigment contents in micropropagated plants of Moringa olifera

Drought induced by addition of different levels of mannitol significantly decreased $\mathrm{Chl}$ a, Chl b and carotenoid contents. Such reduction was positively related to the mannitol concentration (Fig. 3). The reduction in Chls a, b and carotenoid levels were about 3-4 folds at $100 \mathrm{mM}$ mannitol, compared with those of the control. However, at $300 \mathrm{mM}$ mannitol, the reduction in $\mathrm{Chl}$ a reached about 6 folds, compared with that of the control, and about 3 folds for both $\mathrm{Chl} \mathrm{b}$ and carotenoids.

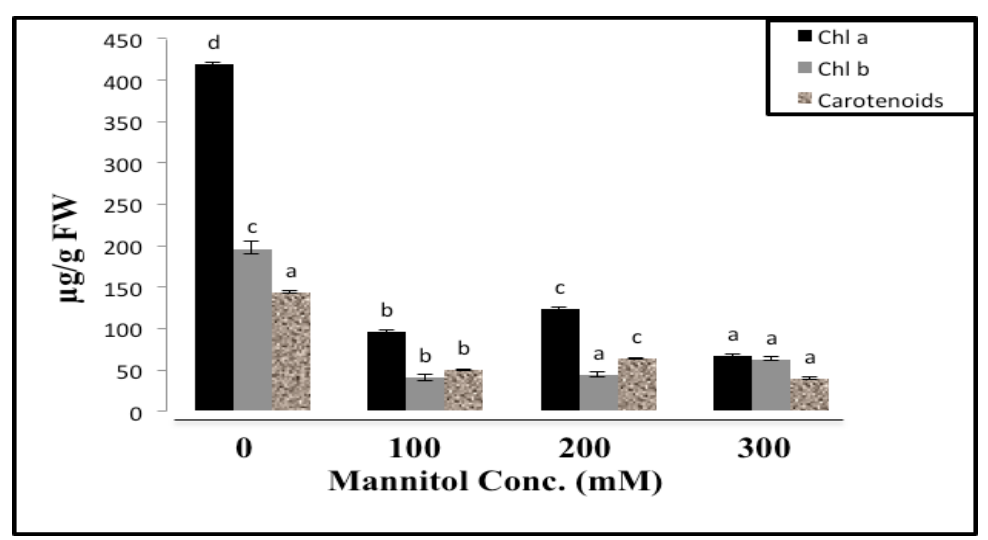

Fig.3. Effect of mannitol induced- drought on pigment contents in micropropagated plants of Moringa olifera. Results are shown as means of three replicates \pm SE. The LSD at $0.05 \%$ level is $2.303,24.466$ and 1.171 in Chl a, b and carotenoids respectively. 
Effect of mannitol-induced drought on soluble sugar, free proline and malondialdehyde in micropropagated plants and callus cells

The total soluble sugar concentration in callus increased proportionally with increasing mannitol in the callus medium (Fig. 4A). In case of micropropagated plantlets, the greatest level of soluble sugar was displayed with $100 \mathrm{mM}$ mannitol. However, no difference in the total soluble sugar contents were detected at $300 \mathrm{mM}$ mannitol and the control. Malonaldehyde concentration increased in micropropagated plantlets with increasing mannitol concentration in a higher pattern than callus (Fig. 4 B).

Furthermore, increasing mannitol concentrations significantly increased the accumulation of free proline in callus cells as well as micropropagated plants (Fig. 4C). The increment in the accumulation of proline was more pronounced at $300 \mathrm{mM}$ followed by $100 \mathrm{mM}$ mannitol.

Effect of mannitol-induced drought on ascorbic acid, glutathione and total phenols in micropropagated plants and callus cells

Figure 5 shows that ascorbic acid and total phenols increased significantly by mannitol treatments. The increment in the levels of ascorbic acid reached about 4.1, 3.8 and 3.4 folds at 100, 200 and $300 \mathrm{mM}$ mannitol respectively compared to control (Fig. 5A). However, GSH increased by $1-7 \%$ of the control with increasing mannitol levels (Fig. 5B). Meanwhile, the increase in total phenols was about 96, 127 and 174\% at 100, 200 and $300 \mathrm{mM}$ mannitol, respectively compared to control (Fig.5C).

In micropropagated plantlets, ascorbic acid was increased by 154,165 and $126 \%$ compared with the control. The maximum increase in ascorbic acid was measured in the plantlets exposed to $100 \mathrm{mM}$ mannitol, whereas GSH levels increased by $1-4 \%$ of the control. Moreover, the total phenols level reached about 129, 151 and 139\% at100, 200 and $300 \mathrm{mM}$ mannitol, respectively compared to control (Fig. 5).

Effect of mannitol-induced drought on antioxidant enzymes in micropropagated plants and callus cells

The activities of the antioxidant enzymes exhibited differential response patterns to drought induced by mannitol as shown in Fig. 6. In callus, some enzyme activities slightly increased like CAT or decreased like APX, POX and ASO, while, PPO increased only at 100 and $200 \mathrm{mM}$ mannitol. Among others, increment in SOD activity was more pronounced.

In micropropagated plantlets, some enzyme activities including CAT and APX showed similar responses as those in callus. But, SOD activity increased compared with that in callus. However, some enzyme activities responded differently like POX and ASO as they increased to some extents compared to their activities in callus.

Egypt. J. Bot., 56, No. 3 (2016) 


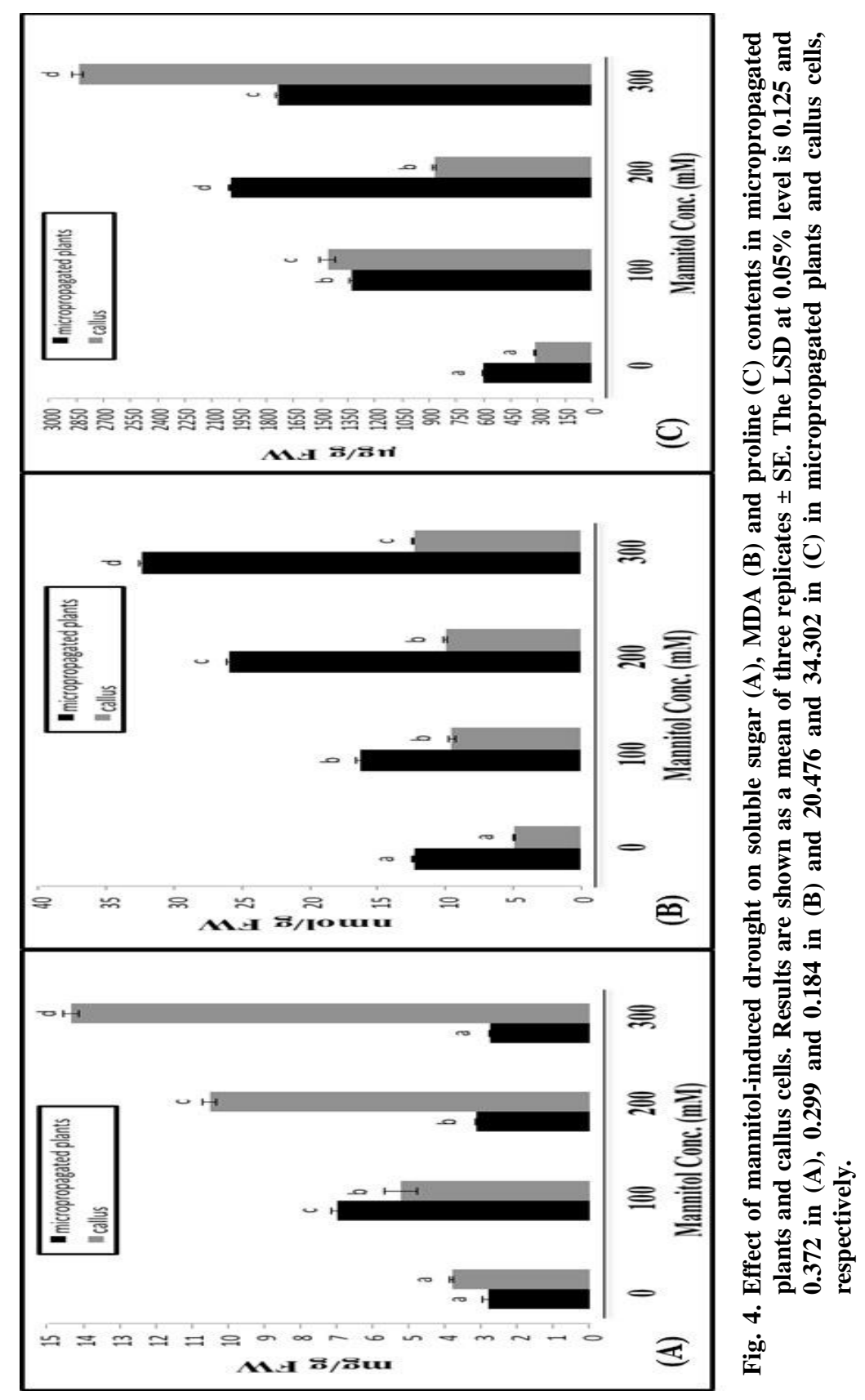

Egypt. J. Bot., 56, No. 3 (2016) 


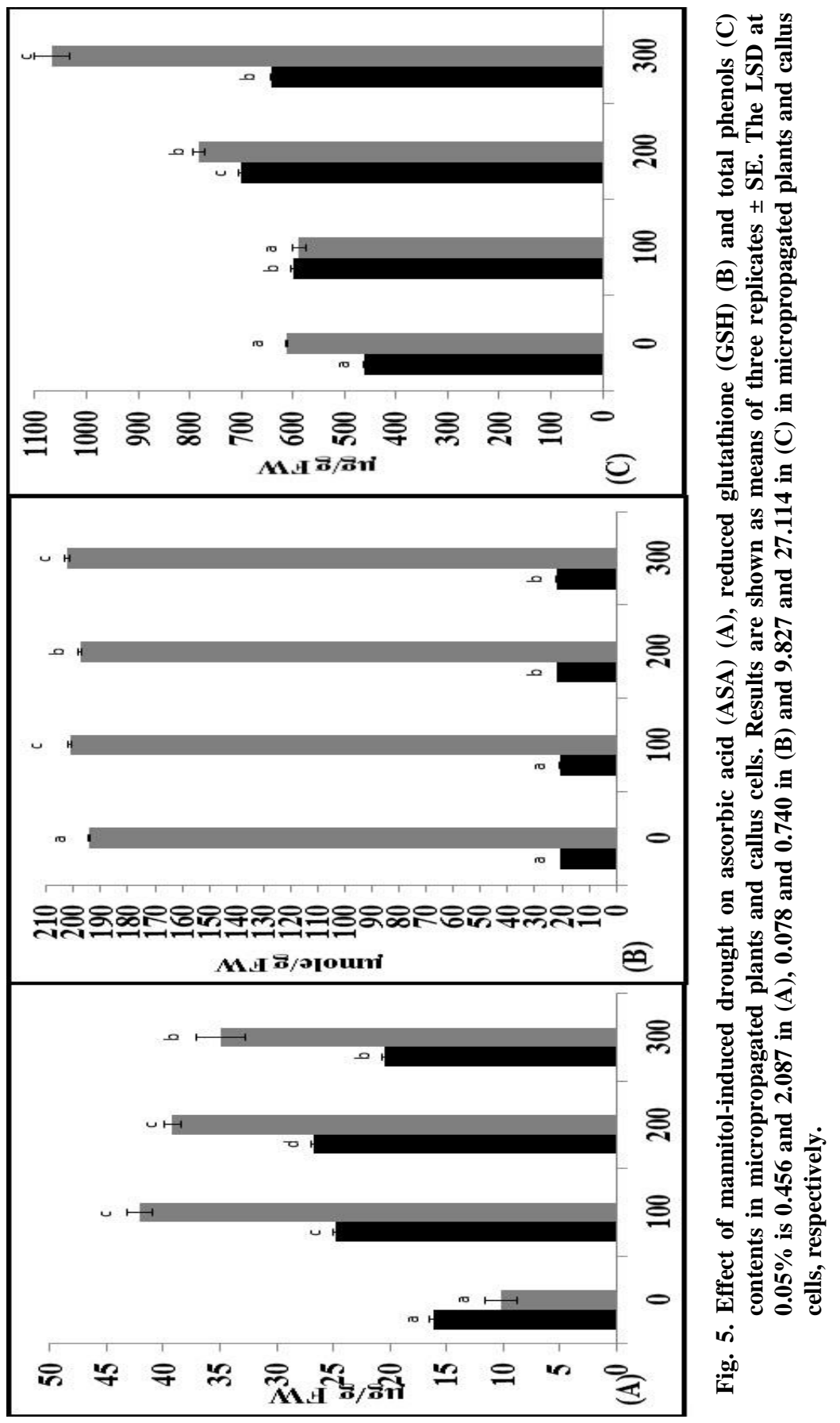

Egypt. J. Bot., 56, No. 3 (2016) 

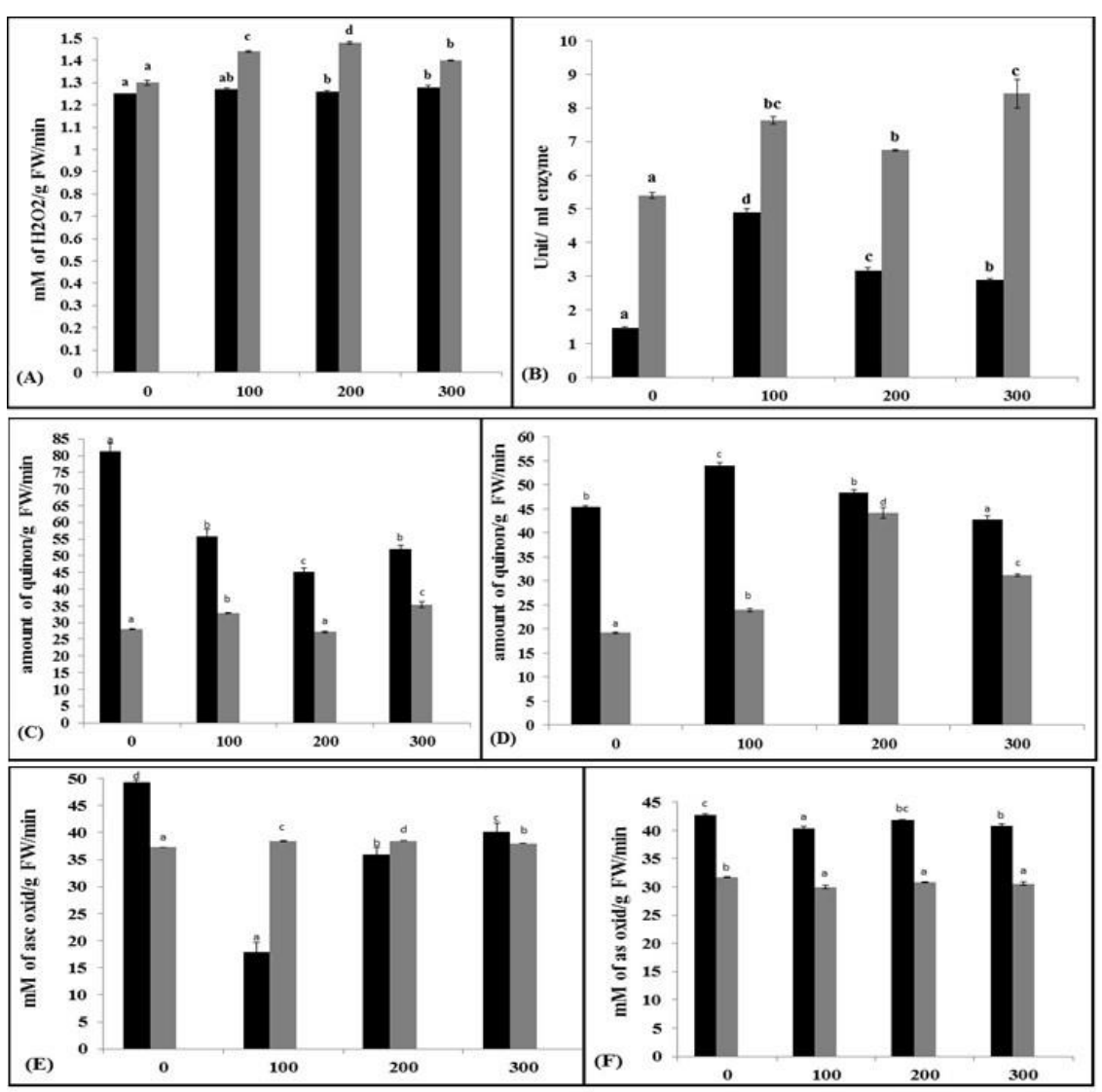

Fig. 6. Effect of mannitol-induced drought on catalase (CAT) (A), superoxide dismutase (SOD) (B) peroxidas (POX) (C), polyphenol oxidase (PPO) (D), ascorbate oxidase (ASO) (E) and (ascorbate peroxidase) APX (F) enzyme activities in micropropagated plants and callus cells of Moringa. Results are shown as a mean of three replicates \pm SE. The LSD at $0.05 \%$ is 0.007 and 0.009 in (A), 0.110 and 0.325 in (B) and 2.366 and 0.704 in (C), 0.764 and 0.854 in (D), 1.885 and 0.091 in $(E), 0.347$ and 0.288 in $(F)$ in micropropagated plants and callus cells respectively.

\section{Discussion}

Drought stress is one of the major factors limiting the growth of cultivated plants. Drought affects plant physiology and biochemistry and causes a decrease in the efficiency of plant growth and prodcutivity (Arora et al., 2002). The exposure to drought stress induced reduction in the shoot growth (Sankar et al., 
2007; Akcay et al., 2010 and Kavas et al., 2013). This reduction was sometimes parallel to inhibition in root growth. In the present study, a decline in root length of Moringa oleifera exposed to mannitol-induced drought stress was noticed (Table 4). This might be ascribed to the reduction in cell elongation resulted from reduction in turgor induced by water deficit (Berg and Zeng, 2006). Moreover, our results showed reduction in shoot length during stress conditions at all mannitol levels, which might be attributed to water stress, decreased cell division and enlargement due to low turgor pressure (Manivannan et al., 2007a and Sankar et al., 2007) and these results might indicate a trend of recovery from drought effect with laps of time.

Likewise, drought stress induced by mannitol generally caused reduction in fresh and dry weights of both shoots and roots (Table 4). Devi and Giridhar (2015) reported that drought stress reduced root and shoot fresh and dry weight in Indian soybean varieties. Such increase in root weight provides a relatively large absorption surface and alleviates the stress effect. However, the reduction in dry weight as a result of stress might be attributed to the alteration in carbon and nitrogen allocation and partitioning (Kluge, 1976 and Jaleel, 2009), similar responses in callus tissue of many plants have been shown by Khalequzzaman et al. (2005), Sakthiv et al. (2008) and Wani et al. (2010).

Chlorophyll content in plants is an important factor in determining photosynthetic capacity. The reduction in chlorophyll content is a typical symptom of oxidative stress and one of the adaptation strategies of plants in order to protect the possible photo-inhibition/ photo-dynamic damage during stress conditions (Munne-Bosch and Alegre, 1999).The loss of chlorophyll was attributed to the photoprotection of the photosystem two of light reactions of photosynthesis (Thomas and Stoddart, 1980).

Water deficit induced significant reduction in chlorophyll a and b contents in the present study (Fig. 3). Such effect might be ascribed to loss of chloroplast membranes, excessive swelling, distortion of the lamellae vesiculation, and the appearance of lipid droplets (Kaiser et al., 1981).In this respect, drought stress caused significant decrease in chlorophyll content in leaves of pea (Karatas et al., 2014). Low concentrations of photosynthetic pigments can directly limit photosynthetic potential and hence primary production and/or the production of peroxidative enzymes associated with the degradation of chlorophyll in the thylakoid membrane (Gandul-Kojas et al., 2004).

In plants, the osmotic adjustment contributes to the maintenance of pressure during the drought period. Different compounds play a role in osmotic adjustment such as quaternary amines, amino acids, proline and soluble sugar (Cherian et al., 2006). The present study revealed that the imposition of drought by mannitol significantly increased soluble sugar content in both callus cells and micropropagated plants. The percentage of increase was found to be higher in callus cells than micropropagated plants (Fig. 4A). This result is in

Egypt. J. Bot., 56, No. 3 (2016) 
accordance with those of Shehab et al. (2010), who reported that drought stress increased the content of soluble sugars in rice (Oryza sativa). In fact, soluble sugars serve as important osmoregulators that can adjust osmotic potential and improve stability of proteins. Soluble sugars are not only involved in storage functions but also contribute in controlling cellular metabolism (Harding et al., 2003 and Shao et al., 2005 a, b and c).

Moreover, drought stress negatively affects many aspects of cellular physiology. The major responses to water deficit stress are ROS accumulation, membrane damage and altered antioxidant enzymatic activity, which subsequently lead to the loss of membrane integrity (Li et al., 2011 and Jdey et al., 2014). Lipid peroxidation is considered as a primary cause of membrane oxidative degradation. Malondialdehyde MDA is the product of lipid peroxidation, considered as an indicator of membrane damage (Zhang and Kirkham 1996 and Guo et al. 2006). Lipid peroxidation induces free radical as superoxide radical and hydrogen peroxide at the cellular level and may change permeability and composition of membranes. The results of the present investigation showed that, the levels of MDA accumulation was positively related to the extent of mannitol-induced drought stress. Such effect suggests that drought stress caused membrane damage in both micropropagated plants and callus cells. The increments in MDA values were more pronounced in the micropropagated plants than the callus cells (Fig. 4B), which suggested that the formers were more sensitive to drought stress than the callus cells. Shehab et al. (2010) observed that drought stress resulted in a markedly increased MDA as a response to elevated oxidative damage promoted by lipid peroxidation under free radical formation.

The accumulation of proline under abiotic stress conditions varied depending on the species and the extent of stress responce. Proline is an osmolyte that plays a diverse role in the reduction of water potential, osmoprotecting, stabilization of proteins, membranes and subcellular structures, and protecting cellular functions by scavenging ROS (Reactive Oxygen Species) (KaviKishor et al., 2005 and Nikolaeva et al., 2010). Proline accumulation was correlated to a variety of stress conditions and is now regarded as a major non-enzymatic antioxidant (Szabados and Savouré, 2010). Proline content increased significantly under drought and severe salt stress conditions in Ailanthus altissima seedlings, supporting its role as a protective agent under oxidative stress conditions (De Carvalho et al., 2013). These data was consistent with our results, which showed the accumulation of proline under drought stress condition, particularly in callus cells (Fig. 4C). It was concluded that plants accumulate compatible solutes, such as proline, in response to stresses to facilitate water uptake, protect cells against oxidative 
damage and alleviate the negative effect of drought stress on water status and plant growth (Ashraf and Foolad, 2007).

To minimize the effects of oxidative stress, plants have evolved an antioxidant system comprising low molecular antioxidant substances including carotenoids, phenols, ascorbic acid and GSH as well as ROS scavenging enzymes, such as superoxide dismutase, peroxidase and catalase (Apel and Hirt, 2004). Our data show the differential responses in the antioxidant enzyme activities reflecting the different antioxidant metabolism in response to drought stress.

Significant increase in glutathione (GSH) content was recorded in both micpropagated plants and callus cells exposed to mannitol-induced drought stress (Fig. 5B). Glutathione plays a protective role in scavenging singlet oxygen, peroxides and hydroxyl radicals as it is involved in the ascorbateglutathione pathway in chloroplasts (Foyer, 1993).

In addition, the activities of both superoxide dismutase and catalase were markedly increased in both drought stressed micropropagated plants and callus cells exposed to different levels of mannitol (Fig. 6 A\& B).

Superoxide dismutase neutralizes the superoxide radical in the chloroplast and catalyzes the first step in the detoxification of active oxygen forming $\mathrm{H}_{2} \mathrm{O}_{2}$. Hydrogen peroxide is then scavenged by catalase, resulting in the dismutation of $\mathrm{H}_{2} \mathrm{O}_{2}$ to water and oxygen. Peroxidase (POX) enzyme plays a vital role in decomposition of $\mathrm{H}_{2} \mathrm{O}_{2}$ toxicity to water and molecular oxygen $\left(\mathrm{O}_{2}\right)$ hence, preventing the cellular damage under water deficit stress (Frederick et al., 2001 and Mohsenzadeh et al., 2006). In the present study, a significant increase in POX activity was measured in callus cells (Fig. 6C). In contrast, the POX activity was decreased in micpropagated plants under drought stress induced by mannitol. This reduction was concomitant with a pronounced increase in the total phenols contents which are substrates for POX and PPO enzymes. Phenolic compounds are antioxidants being able to neutralize the activated and toxic reactive oxygen species (Ksouri et al., 2011).These results are in accordance with those of Karatas et al. (2014) who found that drought stress markedly enhanced the activities of SOD, CAT, POX but slightly changed the activity of APX in pea (Pisum sativum L.).

Among the non-enzymatic antioxidants, ascorbate is one of the best characterized compounds, required for many key metabolic functions in plant cells (Smirnoff and Wheeler, 2000). In the present study, drought stress induced by mannitol stimulated the production of ascorbic acid content in both micpropagated plants and callus cells (Fig. 5A). The reduction in APX and ASO activities reflected the increases in ASA levels. Ascorbic acid acts as an antioxidant, protecting cells against oxidative stress. ASA has the capacity to eliminate different ROS including singlet oxygen, superoxide and hydroxyl radicals (Foyer, 2001).

Egypt. J. Bot., 56, №. 3 (2016) 


\section{References}

Akcay, U.C., Ercan, O., Kavas, M., Yildiz, L., Yilmaz, C., Oktem, H.A. and Yucel, M., (2010) Drought-induced oxidative damage and antioxidant responses in peanut (Arachis lypogaea L.) seedlings. Plant Growth Regul, 61, 21-28.

Apel, K. and Hirt, H., (2004) Reactive oxygen species: metabolism, oxidative stress and signal transduction. Annu. Rev. Plant Biol. 55, 373-399.

Araus, J.L., Slafer, G.A., Reynolds, M.P. and Royo, C., (2002) Plant breeding and drought in $\mathrm{C}_{3}$ cereals: What should we breed for?. Annals of Botany, (89), 925-940.

Arora, A., Sairam, R.K. and Srivastava, G.C., (2002) Oxidative stress and antioxidative systems in Plants. Curr. Sci., 82,1227-1238.

Ashraf, M. and Foolad, M.R., (2007) Roles of glycine betaine and proline in improving plant abiotic stress resistance. Environ. Exper. Bot., 59, 206-216.

Bates, L.S., Waldren, R.P. and Tear, I.D., (1973) Rapid determination of free proline for water-stress studies. Plant and Soil., 39, 205-207.

Berg L.V.D. and Zeng Y.J., (2006) Response of south african indigenous grass species to drought stress induced by polyethylene glycol (PEG) 6000, S. Afr. J. Bot.,72, 284286.

Blakeney, A.B. and Mutton, L.L., (1980) A Simple calorimetric method for the determination of sugars in fruits and vegetables. J. Sci. Food Agric., 31, 889-897.

Boyer, J.S., (1982) Plant prod. environ. Sci., 218, 443-448.

Chen, Y., Cao, X.D., Lu, Y. and Wang, X.R., (2000) Effects of rare earth metal ions and their EDTA complexes on antioxidant enzymes of fish liver. Bull. Environ. Contam. Toxicol., 65, 357-365.

Cherian, S., Reddy, M.P. and Ferreira, R.B., (2006) Transgenic plants with improved dehydration-stress tolerance: Progress and Future Prospects. Biologia Plantarum, 50, 481-495.

De Carvalho, K., De Campos, M.K.F., Domingues, D.S., Pereira, L.F.P. and Vieira, L.G.E., (2013). The accumulation of endogenous proline induces changes in gene expression of several antioxidant enzymes in leaves of transgenic Swinglecitrumelo. Mol. Biol. Reports, 40, 3269-3279.

Devi, M.K.A. and Giridhar, P., (2015) Variations in physiological response, lipid peroxidation, antioxidant enzyme activities, proline and isoflavones content in soybean varieties subjected to drought stress. Proc. Nat. Acad. Sci. India, Sect. B: Biol. Sci., 85, 35-44. 
Diallinas, G., Pateraki, I., Sanmartin, M., Scossa, A., Stillianou, E., Panopoulos, N.J. and Kanellis, A.K., (1997) Melon ascorbate oxidase: cloning of a multigen family, Induction during fruit development and repression by wounding. Plant Mol. Biol., 34, 759-770.

Ehsanpour,A.A. and Amini, F., (2003) Effect of salt and drought stress on acid phosphatase activities in alfalfa (Medicago sativa L.) explants under in vitro culture. Af. J. Biotechnology, 2(5),133-135.

Foyer, C. H. (1993) Ascorbic Acid, In: Alscher, R. G., Hess, J.L., (Eds.). Antioxidants in Higher Plants. CRC Press, Florida, USA. pp. 31-58.

Foyer, C. H. (2001) Prospects for enhancement of the soluble antioxidants, ascorbate and glutathione. Bio Fac., 15, 75-78.

Frederick J.R, Camp C.R. and Bauer P.J., (2001) Drought-stress effects on branch and main stem seed yield and yield components of determinate soybean, Crop Sci. 41, 759-763.

Gandul-Rajas, B., Roca, M. and Minguez-Mosquera, M.I., (2004) Chlorophyll and carotenoid degradation mediated by thylakoid-associated peroxidative activity in olives (Olea europaea) cv. Hojiblance. J. Plant Physiol., 161, 499-507.

Guo, Z., Ou, W., Lu, S., Zhong, Q., (2006) Differential responses of antioxidative system to chilling and drought in four rice cultivars differing in sensitivity. Plant Physiol. Biochem., 44, 828-836.

Harding, H. P., Zhang, Y.H. and Zeng, H.Q., (2003) An integrated stress response regulates amino acid metabolism resistance to oxidative stress. Mol. Cell., 11, 619633.

Heath, R.L. and Packer, L., (1968) Photo peroxidation in isolated chloroplasts. I. kinetics and stochiometry of fatty acid peroxidation. Arch. Biochem. Biophys. 125, 189-198.

Hissin, P.J. and Hilf, R., (1976) A Fluormetric Method for determination of oxidized and reduced glutathione in tissues. Ann. Biochem., 74, 214-226.

Homme, P.M., Gonalez, B. and Billard, J., (1992) Carbohydrate content, fructane and sucrose enzyme activities in roots, stubble and leaves of rye grass (Lolium perenne L.) as affected by source/sink modification after cutting. J. Plant Physiol., 140, 282-291.

Islam, T., Dembele, P. and Keller, J., (2005) Influence of explant, temperature and different culture vessels on in vitro .culture for germplasm maintenance of four mint accessions. Plant Cell, Tissue and Organ Culture., 81,123-130.

Jaleel, C.A., P. Manivannan, A. Wahid, M. Farooq, R. Somasundaram and R. Panneerselvam, (2009) Drought stress in plants: a review on morphological characteristics and pigments composition. Int. J. Agric. Biol., 11, 100-105. 
Jauhar P.P., (2005) Modern biotechnology as an integral supplement to conventional plant breeding: the prospects and challenges. Crop Sci., 46 (4), 1841-1859.

Jdey, A., Slama, I., Rouached, A. and Abdelly, C., (2014) Growth, Na+, K+, osmolyte accumulation and lipid membrane peroxidation of two provenances of Cakilemaritima during water deficit stress and subsequent recovery. Flora., 209, 54-62.

Kaiser, W.M., Kaiser, G., Schoner, S. and Neimanis, S., (1981) Photosynthesis under osmotic stress. differential recovery of photosynthetic activities of stroma enzymes, intact chloroplasts and leaf slices after exposure to high solute concentrations. Planta., 153, 430-435.

Kar, M., Mishra, D., (1976) Catalase, peroxidase and polyphenol oxidase activities during Rice leaf senescence. Plant Physiol., 57, 315-319.

Karatas, I., Öztürk, L., Demir, Y., Unlükara, A., Kurunç, A. and Düzdemir, O., (2014) Alterations in antioxidant enzyme activities and proline content in Pea leaves under long-term drought stress. Toxicol. Indust. Health., 30, 693-700.

Kavas, M., Baloğlu, M.C., Akça, O., Kose, F.S. and Gökçay, D., (2013) Effect of drought stress on oxidative damage and antioxidant enzyme activity in Melon seedlings. Turk. J. Biol., 37, 491-498.

Kavi Kishor, P.B., Sangam, S., Amrutha, R.N., Laxmi, P.S., Naidu, K.R. and Rao, K.R.S.S., (2005) Regulation of proline biosynthesis, degradation, uptake and transport in higher plants: Its implications in plant growth and abiotic stress tolerance. Curr. Sci., 88, 424-438.

Keer, W.E. and Silva, A.R., (1999) Moringa: uma nova hortaliça para o Brasil. Uberlândia: UFU/DIRIU.

Khalequzzaman, M., Haq, Hoque, M.E. and Aditya, TL., (2005) Regeneration efficiency and genotypic effect of 15 Indica type Bangladeshi rice (Oryza sativa L.) Landraces. Plant Tiss. Cult., 15, 33-42.

Kluge, M., (1976) "Water and Plant Life-ecological Studies" Vol. 19 (Springer-VerlagBerlin). 243.

Koricheva, J., Roy, S., Vranjic, J.A., Haukioja, E., Hughes, P.R. and Hanninen, O., (1997) Antioxidant responses to simulated acid rain and heavy metal deposition in Brich seedlings. Environ. Poll., 95, 249-258.

Ksouri, R., Megdiche, K.W., Jallali, I., Debez, A., Magné, C., Hiroko, I. and Abdelly, C., (2011) Medicinal halophytes: potent source of health promoting biomolecules with medical, nutraceutical and food applications. Crit. Rev. Biotech., 1-38. 
Li,Y., Zhao, H.X., Duan, B.L., Korpelainen, H. and Li, C.Y., (2011) Effect of drought and aba on growth, photosynthesis and antioxidant system of cotinuscoggygria seedlings under two different light conditions. Environ. Exp. Bot., 71, 107-113.

Malik, C.P. and Singh, M.B., (1980) In: "Plant Enzymology and Histo-nzymology". Kalyani Publishers. New Delhi, p. 286.

Manivannan, P., Jaleel, C.A., Sankar, B., Kishorekumar, A., Somasundaram, R., Lakshmanan, G.M.A. and Panneerselvam, R., (2007) Growth, biochemical modifications and proline metabolism in Helianthus annuus L. as induced by drought stress. Colloids and surfaces B: Biointerfaces., 59, 141-149.

Marfori, E.C., (2010) Clonal micropropagation of Moringa olifera L. The Philippine Agricultural Scientist., 93, 454-457.

Marklund, S. and Marklund, G., (1974) Involvement of the superoxide anion radical in the autoxidation of pyrogallol and a convenient assay for superoxide dismutase. Eur. J. Biochem., 47, 469-474.

Metzner, H., Rau, H., Senger, H., (1965) Uentersuchungen zur synchronisier barkeit einzelner-pigment. mangol mutanten von chloella. Planta, 65, 186-194.

Moffat, A.S., (1996) Ecology: biodiversity is a boon to ecosystems, not species. Science., 271, 1497.

Mohsenzadeh, S., Malboobi, M. A., Razavi, K. and Farrahani-Aschtiani, S. (2006). Physiological and molecular responses of Aeluropus lagopoides (Poaceae) to water deficit. Environ. Exper. Bot., 56, 314-322.

Morton, J.F., (1991) The horseradish tree,Moringa pterygosperma (Moringaceae) -A boon to Arid Lands?Economic Botany., 45,318-333.

Mukheriee, S.P. and Choudhuri, M.A., (1983) Implication of water stress-induced changes in the level of endogenous ascorbic acid and hydrogen peroxide in Vigna seedling. Physiol. Plant., 58, 166-170.

Munne-Bosch, S. and Alegre, L., (1999) Role of dew on the recovery of water-stressed Melissa officinalis L. plants. J. Plant Physiol., 154, 759-766.

Mylene C. N. and Evalour T. A., (2011) Callus Induction in Cotyledons of Moringa oleifera Lam. Philipp. Agric. Scientist., 94(3), 239-247.

Nikolaeva, M.K., Maevskaya, S.N., Shugaev, A.G. and Bukhov, N.G., (2010) Effect of drought on chlorophyll content and antioxidant enzyme activities in leaves of three Wheat cultivars varying in productivity. Russian J. Plant Physiol., 57, 87-95.

Sankar, B., Jaleel, C.A., Manivannan, P., Kishorekumar, A., Somasundaram, R. and Panneerselvam, R., (2007) Effect of paclobutrazol on water stress amelioration through antioxidants and free radical scavenging enzymes in Arachis hypogaea L. Colloids Surf. B: Biointerface, 60, 229-235. 
Shabir H. Wani, Parvez A. Sofi, Satbir S. Gosal and Naorem B. Singh. (2010) In vitro screening of rice (Oryza sativa L) callus for drought tolerance. Commun. Biometry Crop Sci., 5(2), 108-115.

Shao, H. B., Liang, Z.S., Shao, M.A. (2005b) LEA protein: structure, function and gene expression and regulation. Colloid Surf. B: Biointerf., 45, 131-135.

Saini, J., Arya, S. and Singh, S. (2013) In vitro regeneration of Moringa olifera: a pharmaceutical important shrub. Asian J Biochem. Pharm. Res., 3, 56-62.

Shao, H. B., Liang, Z.S. and Shao, M.A., (2005c) Adaptation of higher plants to environmental stresses and stress signal transduction. Act. Ecol. Sin., 25, 1772-1781.

Shao, H. B., Liang, Z.S. and Shao, M.A., (2005a) Change of antioxidative enzymes and MDA among 10 Wheat genotypes at maturation stage under soil water deficits. Colloid. Surf. B: Biointerf, 45, 7-13.

Shehab, G.G., Ahmed, O. K. and El-Beltagi, H. S., (2010) Effects of various chemical agents for alleviation of drought stress in Rice plants (Oryza sativa L.). Not. Bot. Hort. Agrobot. Cluj., 38, 139-148.

Smirnoff, N., Wheeler, G.L., (2000) Ascorbic acid in plants: biosynthesis and function. Crit. Rev. Plant Sci., 19, 267-290.

Stephenson, K. and Fahey, J.W., (2004) Development of tissue culture methods for the rescue and propagation of endangered Moringa Spp. Germplasm. Econ. Bot. 58, 116-124.

Sundar, I.K. and Sakthivel, N., (2008) Advances in selectable marker genes for plant transformation. J. Plant Physiol., 165, 1698-1716.

Szabados, L. and Savouré, A., (2010) Proline: A multifunctional amino acid. Trend Plant Sci., 15, 89-97.

Thomas, H. and Stoddart, J.L., (1980) Leaf senescence. Annu. Rev. Plant Physiol., 31, 83-111.

Zang, Komatsu (2007) A proteomics approach for identifying osmotic-stress-related proteins in rice. Phytochemistry., 64, 426-437.

Zhang, J. and Kirkham, M.B., (1996) Antioxidant responses to drought in sunflower and sorghum seedlings. New Phytol., 132, 361-373.

(Received 24/1/2016; accpted 15/3/2016) 


\title{
إستجابة كل من كالوس وأكثار نبات المورينجا أوليفيرا لإجهاد الجفاف المستحث بالمانيتول
}

\author{
حنان فريد محمود شعبان و نسمه ماهر

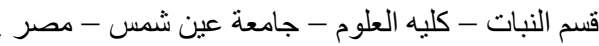

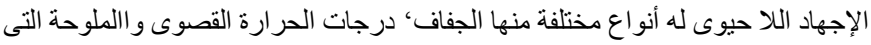

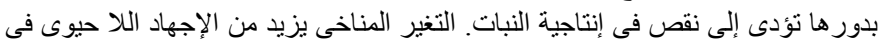

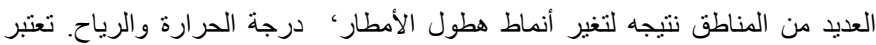

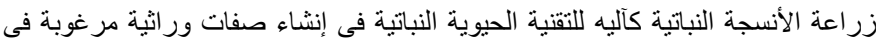

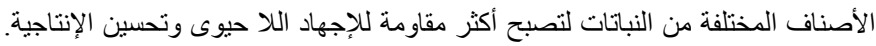

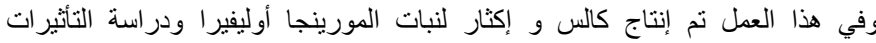

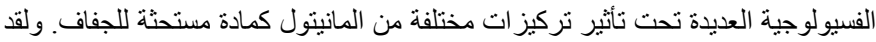

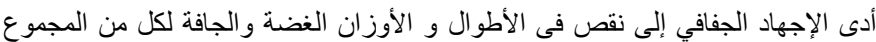

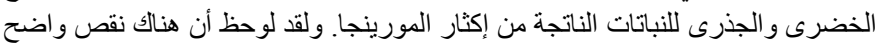

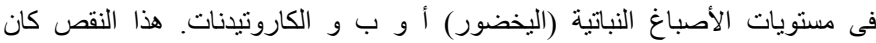

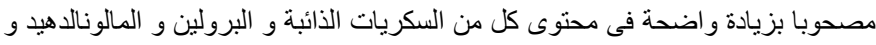

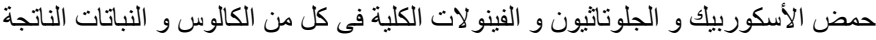

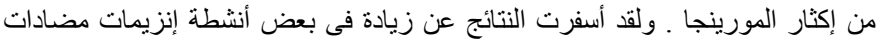

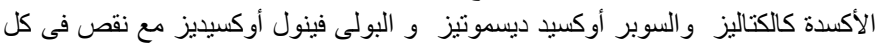

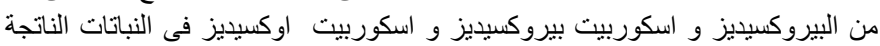

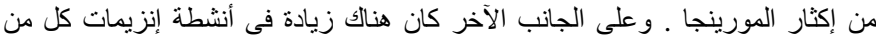

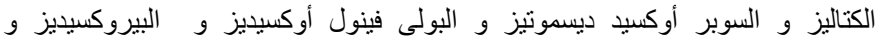

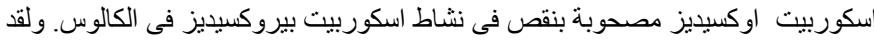

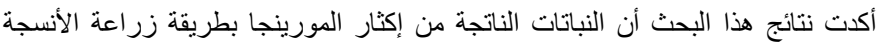

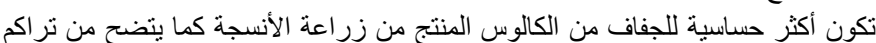

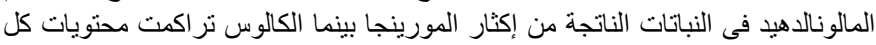

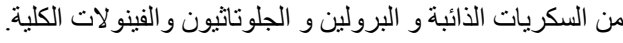

